\title{
AVALIAÇÃO DA APRENDIZAGEM ESCOLAR: COMO OS PROFESSORES ESTÃO PRATICANDO A AVALIAÇÃO NA ESCOLA
}

C. E. L. DUARTE
Instituto Federal do Rio Grande do Norte
carlos.duarte@ifrn.edu.br
Artigo submetido em setembro/2013 e aceito em dezembro/2015
DOI: $10.15628 /$ holos.2015.1660

\section{RESUMO}

A avaliação da aprendizagem escolar, obedecendo a um modelo de sociedade autoritário, tem sido utilizada, equivocadamente, como um instrumento disciplinador $\mathrm{e}$ classificatório, fazendo com que a reprovação deixe de ser um caso excepcional para ser uma rotina na escola. Através de uma pesquisa junto aos professores dos anos finais do ensino fundamental, constatou-se que a prática da avaliação nas escolas está muito distante da ação avaliativa diagnóstica e formativa. É preciso - e urgente - uma mudança na postura dos professores no que diz respeito à prática avaliativa para que a escola possa ser, de fato, formadora de cidadãos críticos e conscientes de seu papel na sociedade.

PALAVRAS-CHAVE: Avaliação, ensino-aprendizagem, diagnóstico, instrumentos avaliativos.

\section{EVALUATION OF LEARNING SCHOOL: HOW TEACHERS ARE PRACTICING THE EVALUATION IN SCHOOL}

\section{ABSTRACT}

The evaluation of the pertaining to school learning, obeying a model of authoritarian society, has been used, in maken a mistake way, as a disciplinarian instrument and classificatory, making with that the reproves leaves of being a bonanza case to be a routine in the school. Through a research next to the teachers of the final years of basic education, one evidence that the practical one of
\end{abstract}

the evaluation in the schools is very distant of the diagnostic and formative evaluative action. It's necessary - and urgent - a change in the position of the teachers in what it says respect to the practical evaluative so that the school can be, in fact, formatter of critical and conscientious citizens of its paper in the society.

KEYWORDS: evaluation, teach-learning, diagnostic, evaluation instruments. 


\section{INTRODUÇÃO}

A avaliação é um instrumento fundamental para fornecer informações sobre como está se realizando o processo ensino-aprendizagem em seu todo e não deve simplesmente focalizar o aluno, seu desempenho cognitivo e o acúmulo de conteúdo, para classificá-lo em aprovado ou reprovado, isto é, a avaliação não deve servir apenas para observar o aluno, mas todos os envolvidos no processo de ensino-aprendizagem. Contudo, neste caso, enfatizamos a relação professor-aluno e o percurso de avaliação discente.

A avaliação vista como um diagnóstico contínuo e dinâmico torna-se um instrumento fundamental para repensar e reformular os métodos, os procedimentos e as estratégias de ensino para que, de fato, o aluno aprenda. Além disso, ela deve ser essencialmente formativa, na medida em que cabe à avaliação subsidiar o trabalho pedagógico, redirecionando o processo ensinoaprendizagem para sanar dificuldades, aperfeiçoando-o constantemente.

Nessa perspectiva, a avaliação precisa deixar de ter o caráter classificatório de simplesmente aferir acúmulo de conhecimento para promover ou reter o aluno. Ela deve ser entendida pelo professor como processo de acompanhamento e compreensão dos avanços, dos limites e das dificuldades dos alunos para atingirem os objetivos da atividade de que participam.

Contudo, na prática escolar, a avaliação recebeu um status muito elevado, como se ela fosse a finalidade do ensino. Para averiguar essa situação, realizamos esse trabalho com o objetivo de analisar a atual prática da avaliação por parte dos professores do Ensino Fundamental II no contexto escolar. Para isso, buscamos verificar qual o conceito de avaliação presente entre os professores, identificar os critérios utilizados por eles para a elaboração de um instrumento avaliativo, verificar suas visões acerca da relação entre notas e aprendizagem e analisar a visão dos docentes sobre a reprovação.

\section{O ATUAL CONTEXTO DA AVALIAÇÃO}

A sociedade, ao longo do tempo, organiza-se e reorganiza-se conforme mudanças na realidade histórica, política e econômica. Assim sendo, atualmente, é impossível compreender a educação escolar (e a avaliação) sem atentarmos para a globalização e a ideologia de livre mercado (neoliberalismo), que imperam na sociedade contemporânea.

As políticas educacionais brasileiras demonstram sua centralidade na hegemonia das ideias neoliberais sobre a sociedade. Prova disso são as mudanças que, aos poucos, vão sendo percebidas na educação. Vejamos algumas: formação cada vez menos abrangente e mais profissionalizante; aumento de matrículas como jogo de marketing (são feitas cada vez mais inscrições sem que haja uma estrutura efetiva para novas vagas); produtividade e eficiência empresarial (máximo resultado com o menor custo, não interessando o conhecimento crítico).

Segundo Libâneo (2006, p.55),

o governo brasileiro vem implementando suas políticas econômicas e educacionais de ajuste, ou seja, diretrizes e medidas pelas quais o país se moderniza, adquire as condições de inserção no mundo globalizado e, assim, se ajusta às exigências de globalização da economia estabelecidas pelas instituições financeiras e pelas corporações internacionais. 
Em todas essas políticas, o que se vê é o discurso da modernização educativa, da competitividade, da produtividade, da eficiência e da qualidade dos sistemas educativos, da escola e do ensino, na ótica das reformas neoliberais de adequação às exigências do mercado.

Por isso, Luckesi (2005) afirma que a prática escolar predominante hoje se realiza dentro de um modelo de educação que se apresenta como um mecanismo de conservação e reprodução da sociedade. Esse modelo conservador da sociedade produziu três pedagogias diferentes; a pedagogia tradicional, centrada na transmissão de conteúdo e na pessoa do professor; a pedagogia escolanovista, centrada na espontaneidade da produção do conhecimento e no educando; e a pedagogia tecnicista, centrada nas técnicas de transmissão e apreensão dos conteúdos e no princípio do rendimento. Porém com um mesmo objetivo: conservar a sociedade na sua configuração. Essas três pedagogias, por estarem dentro desse modelo social conservador, não poderiam propor nem exercitar tentativas de transcendê-lo, superando-o.

A avaliação da aprendizagem escolar está inserida nesse contexto, o qual necessita do autoritarismo como modo de reprodução desse modelo. Segundo Luckesi (2005, p.28),

é certo que o atual exercício da avaliação escolar não está sendo efetuado gratuitamente. Está a serviço de uma pedagogia, que nada mais é que uma concepção teórica da educação, que, por sua vez, traduz uma concepção teórica da sociedade.

Assim, a avaliação educacional ainda vem sendo utilizada como um instrumento disciplinador de condutas cognitivas e sociais, no contexto escolar.

\section{CONCEITO DE AVALIAÇÃO E SUAS FUNÇÕES}

Avaliar vem do latim a valere, que significa atribuir valor e mérito ao objeto de estudo. Segundo Luckesi (2005), a avaliação é entendida como um julgamento de valor sobre dados relevantes da realidade, tendo em vista uma tomada de decisão. Os dados relevantes se referem às várias manifestações das situações didáticas, nas quais professor e aluno estão empenhados em atingir os objetivos do ensino. O julgamento de valor sobre esses dados, através da análise dos instrumentos de verificação da aprendizagem como provas, exercícios, respostas dos alunos, realização de atividades etc., permite uma tomada de decisão para o que deve ser feito em seguida.

É essa tomada de decisão, quando usada de forma arbitrária, que causa problemas ao processo avaliativo. Pois, dessa maneira, ela reduz a avaliação a um ato sentencivo e classificatório. Entendemos que a avaliação é classificatória quando ela passa a ter a função estática de classificar o objeto em estudo (no caso, o aluno) num padrão definitivamente determinado. Para Luckesi (2005, p.35), "com a função classificatória, a avaliação constitui-se num instrumento estático e frenador do processo de crescimento".

A avaliação, ao contrário, deve ter três funções básicas: a função diagnóstica, que se refere ao conhecimento da realidade através da observação, diálogo e do desenvolvimento de estratégias que possibilitem a caracterização dos espaços, dos sujeitos, das condições a priori; a função formativa, caracterizada por ações avaliativas que propiciam a formação contínua e sistemática durante o processo; e a função somativa, uma análise conclusiva, donde são somados todos os elementos constitutivos da avaliação. 


\subsection{Função diagnóstica}

A avaliação não pode ser um instrumento para a aprovação ou reprovação dos alunos, mas um instrumento de diagnóstico de sua situação, tendo em vista a definição de encaminhamentos adequados para a sua aprendizagem. De acordo com Luckesi (2005, p.81), para ser diagnóstica, "a avaliação deverá ser assumida como um instrumento de compreensão do estágio de aprendizagem em que se encontra o aluno, tendo em vista tomar decisões suficientes e satisfatórias para que possa avançar no seu processo de aprendizagem".

O diagnóstico se constitui por uma sondagem, projeção e retrospecção da situação de desenvolvimento do aluno, dando-lhe elementos para verificar o que aprendeu e como aprendeu. É uma etapa do processo educacional que tem por objetivo verificar em que medida os conhecimentos anteriores ocorreram e o que se faz necessário planejar para selecionar dificuldades encontradas.

A avaliação diagnóstica é etapa importante para o processo de ensino aprendizagem que segundo Sant'Anna (1995, p.33) "visa determinar a presença ou ausência de habilidades, inclusive buscando detectar pré-requisitos para novas experiências de aprendizagem".

Esta forma de entender e realizar a avaliação da aprendizagem exige que ela seja um instrumento que auxilie no desenvolvimento deste processo e não um instrumento de classificação dos alunos em aprovados ou reprovados.

Ainda segundo Luckesi (2005, p.82),

este é o princípio básico e fundamental para que ela [a avaliação] venha a ser diagnóstica. Assim como é constitutivo do diagnóstico médico estar preocupado com a melhoria da saúde do cliente, também é constitutivo da avaliação da aprendizagem estar atentamente preocupada com o crescimento do educando. Caso contrário, nunca será diagnóstica.

\subsection{Função formativa}

Assim como a avaliação diagnóstica, a avaliação formativa não tem como objetivo classificar ou selecionar. Fundamenta-se nos processos de aprendizagem, em seus aspectos cognitivos, afetivos e relacionais; fundamenta-se em aprendizagens significativas e funcionais que se aplicam em diversos contextos e se atualizam enquanto for preciso para que se continue a aprender. De acordo com Sant'Anna (1995, p.34), ela é chamada de formativa "no sentido que indica como os alunos estão se modificando em direção aos objetivos".

Essa avaliação possibilita informar o aluno e o professor sobre os resultados que estão sendo alcançados durante o desenvolvimento das atividades.

Ainda segundo Sant'Anna (1995), para que se processe a avaliação formativa alguns pontos devem ser observados:

- Seleção dos objetivos e conteúdos distribuídos em pequenas unidades de ensino. 0 aluno deverá conhecer os objetivos para que se engaje no processo.

- Formulação de objetivos com vista à avaliação em termos de comportamento observáveis, estabelecendo critérios de tempo, qualidade e quantidade.

- Elaboração de um quadro ou um esquema teórico que permita a identificação das 
áreas de maiores dificuldades.

- Correção de erros e insuficiências para reforço de comportamentos bem-sucedidos e eliminação de desacertos, assegurando o bom andamento do ensino-aprendizagem.

- Seleção adequada de alternativas terapêuticas para ajudar o aluno a se recuperar de alguma insuficiência no processo ensino-aprendizagem.

\subsection{Função somativa}

A avaliação somativa visa à classificação do aluno ao final da unidade, semestre ou ano letivo, segundo níveis de aproveitamento apresentados. Segundo Zabala (1998, p.200),

a avaliação somativa ou integradora é entendida como um informe global do processo que, a partir do conhecimento inicial (...), manifesta a trajetória seguida pelo aluno, as medidas específicas que foram tomadas, o resultado final de todo o processo e, especialmente, a partir deste conhecimento, as previsões sobre o que é necessário continuar fazendo ou o que é necessário fazer de novo.

Essa avaliação analisa de maneira geral o grau em que os resultados mais amplos têm sido alcançados ao longo e ao final de um curso.

Para Sant'Anna (1995), os objetivos individuais devem servir de base assim como o rendimento apresentado pelo grupo. Por exemplo, se uma quantidade significativa de alunos não correspondem aos resultados desejados, esta habilidade, atitude ou informação deve ser desconsiderada e retomada no novo planejamento, visto que não ocorreu a aprendizagem.

Entendida dessa maneira, a avaliação da aprendizagem escolar é um instrumento fundamental para o desenvolvimento do processo de ensino-aprendizagem. Assim, faz-se necessário buscar os instrumentos avaliativos que melhor se adaptem aos objetivos propostos para uma determinada aprendizagem.

\section{ENSINO E APRENDIZAGEM}

Ensino e aprendizagem são duas etapas de um mesmo processo. Por isso, Freire (2003, p.118) defende a ideia de que "ensinar não é transferir conhecimento, mas criar as possibilidades para a sua produção ou a sua construção". O professor planeja, dirige e controla o processo de ensino, tendo em vista estimular a atividade própria dos alunos para a aprendizagem. Nesta perspectiva, Freire $(2003$, p.118) acrescenta:

\footnotetext{
Meu papel como professor, ao ensinar o conteúdo a ou b, não é apenas o de me esforçar para, com clareza máxima, descrever a substantividade do conteúdo para que o aluno o fixe. Meu papel fundamental, ao falar com clareza sobre o objeto, é incitar o aluno a fim de que ele, com os materiais que ofereço, produza a compreensão do objeto em lugar de recebê-la, na íntegra, de mim. Ele precisa se apropriar da inteligência do conteúdo para que a verdadeira relação de comunicação entre mim, como professor, e ele, como aluno se estabeleça.
}

Para melhor compreensão da dinâmica do processo de ensino-aprendizagem analisamos separadamente cada um dos seus componentes. 


\subsection{Aprendizagem}

Para a condução do processo de ensino, é necessária uma compreensão clara do processo de aprendizagem. Para tanto, é preciso analisar como as pessoas aprendem e quais os fatores internos e externos que a influenciam.

Todas as atividades humanas praticadas no ambiente em que vivem podem levar a uma aprendizagem. Desde que nascemos, em todas as nossas atividades, estamos aprendendo. As crianças aprendem a distinguir sons, a andar, a manipular objetos e brinquedos, a andar. Mais tarde, essas crianças aprendem a nadar, a andar de bicicleta, a ler, a contar. Quando jovens e adultas, elas discutem problemas, aprendem a fazer julgamentos e a tomar decisões, aprendem uma profissão. Enfim, as pessoas estão sempre aprendendo.

A aprendizagem pode ser classificada em dois tipos dependendo de sua natureza. Ela pode ser casual ou organizada. A aprendizagem casual é espontânea, surgindo naturalmente da interação entre as pessoas e com o ambiente em que vivem. Segundo Libâneo (1994, p.82), "pela convivência social, pela observação de objetos e acontecimentos, pelo contato com os meios de comunicação, leituras, conversas etc., as pessoas vão acumulando experiências, adquirindo conhecimentos, formando atitudes e convicções". A aprendizagem organizada, por sua vez, é aquela cuja finalidade é aprender determinados conhecimentos e habilidades. Embora este tipo de aprendizagem possa ocorrer em diversos lugares, é função da escola e do ensino organizar as condições específicas para a transmissão e assimilação de conhecimentos e habilidades.

Essa assimilação de conhecimentos se dá por um processo que Libâneo (1994) chama de "assimilação ativa": processo de percepção, compreensão, reflexão e aplicação que se desenvolve com os meios intelectuais, motivacionais e atitudinais do próprio aluno, sob a direção e orientação do professor. O processo de assimilação de conhecimentos resulta da reflexão proporcionada pela percepção prático-sensorial e pelas ações mentais que caracterizam o pensamento. Assim, a aprendizagem escolar deve ser uma atividade planejada, intencional e dirigida. Corroborando com essa ideia, Freire (2003, p.86) diz que a aprendizagem se dá por uma reflexão crítica sobre o objeto de aprendizagem e acrescenta: "O fundamental é que professor e alunos saibam que a postura deles, do professor e dos alunos, é dialógica, aberta, curiosa, indagadora, e não apassivada, enquanto fala ou enquanto ouve. O que importa é que professor e alunos se assumam epistemologicamente curiosos."

Neste sentido, a avaliação deve deixar de ser apenas uma atividade formal e burocrática de fim de unidade didática e passar a ser uma atividade que irá nortear os trabalhos docente e discente. Daí a importância de um ensino onde predomina a prática reflexiva e crítica.

\subsection{Ensino}

O ensino é uma combinação entre a condução do processo de ensino pelo professor e a assimilação ativa como atividade autônoma do aluno. Segundo Libâneo (1994, p.89), "o processo de ensino é uma atividade de mediação pela qual são providas as condições e os meios para os alunos se tornarem sujeitos ativos na assimilação de conhecimentos".

É importante sempre lembrar que não existe ensino sem aprendizagem, por isso Libâneo (1994, p.91) afirma que "a unidade entre ensino e aprendizagem fica comprometida quando o professor concentra na sua pessoa a exposição da matéria, quando não suscita o envolvimento 
ativo dos alunos". Neste sentido, Freire (2003, p.86) afirma que "o bom professor é aquele que consegue, enquanto fala, trazer o aluno até a intimidade do movimento de seu pensamento". Portanto, é função do professor propiciar essa mediação entre aluno e objeto de estudo no sentido de fazer com que aquele se aproprie criticamente dos conteúdos de aprendizagem.

O ensino deve ter, pelo menos, três funções: organizar os conteúdos para a sua transmissão, de forma que os alunos possam ter uma relação subjetiva com eles; ajudar os alunos a aprenderem de forma autônoma e independente; dirigir e controlar a atividade docente para os objetivos de aprendizagem.

Por outro lado, a atividade de ensino está indissociavelmente ligada à vida social mais ampla, a prática social. Neste sentido, é papel do ensino exercer a mediação entre o indivíduo e a sociedade. Essa mediação significa a explicitação dos objetivos de formação escolar frente às exigências do contexto social, político e cultural, bem como o entendimento de que o domínio de conhecimentos e habilidades é um instrumento coadjuvante para a superação das condições de origem social dos alunos, tanto pela melhoria das condições de vida, como pela luta conjunta para a transformação social.

O professor, nessa perspectiva, deixa de ser apenas um repassador de conteúdos e passa a ser aquele que, através dos conteúdos, irá transformar a aula num momento de reflexão, fazendo com que o aluno deixe de ser um sujeito meramente passivo no processo de ensino-aprendizagem e passe a ser um sujeito ativo nesse processo.

Com um ensino pautado na reflexão, o erro passa a ser um degrau para uma nova aprendizagem em vez de algo a ser punido.

\section{ERRO CONSTRUTIVO E REPROVAÇÃO}

Uma das práticas que tradicionalmente tem acompanhado o erro na escola é o castigo. Isso porque se parte da ideia de que o aluno erra na maioria das vezes porque não sabe, e não sabe porque não prestou atenção na explicação do professor. Daí a justificativa da punição. Pelo menos duas questões se revelam em afirmações desta natureza: a explicação mais recorrente acerca da não aprendizagem, que por sua vez penaliza única e exclusivamente o aluno, numa demonstração implícita de culpar a vítima e avaliar apenas um dos pólos da questão.

Não é discutido, por exemplo, o desempenho do professor ou da escola. E a justificativa deste não aprender recai sobre o aluno, baseado no seu suposto desinteresse, esta visão entende que o castigo constitui-se num dos meios para, literalmente, corrigir a situação.

A esse respeito, Luckesi (2005) mostra que o castigo prevalece no currículo oculto da escola, de forma implícita, mas igualmente perverso, apesar dos mecanismos de proteção contra a violência apontando caminhos para a sua superação. Para ele, o erro é referenciado por um determinado padrão, o que é considerado correto, ou seja, a partir de um parâmetro estabelecido como "certo", portanto o que foge à regra colocada é entendido como erro.

Muitos professores não são conscientes do currículo oculto, assim como é oculto aos alunos. Ele pode estar sendo utilizado na relação pedagógica sem que o professor perceba. Este utiliza a sua experiência para transmitir o conteúdo da disciplina e esta experiência é uma forma de currículo oculto. 
Tradicionalmente na escola o erro aparece como fonte de condenação e castigo. A grande questão é que as punições afetam o desenvolvimento das pessoas na medida em que estes sentimentos podem se estender, em algumas situações pela vida afora das suas vítimas, envolvendo não só a própria punição, mas também a necessidade de castigar os outros a partir da projeção destes sentimentos de culpa e o que é mais grave: nem sempre de forma consciente.

Muitas são as razões que desencadeiam o uso do castigo. A principal está ligada a dificuldade apresentada por um determinado aluno de não ter conseguido aprender um assunto dado, conforme demonstra Luckesi (2005, p.52):

A ideia e a prática do castigo decorrem da concepção de que as condutas de um sujeito - aqui, no caso, o aluno -, que não correspondem a um determinado padrão preestabelecido, merecem ser castigadas, a fim de que ele "pague" por seu erro e "aprenda" a assumir a conduta que seria correta.

Verifica-se que a prática do castigo está ligada à visão culposa das atitudes humanas, onde o erro é a origem da condenação e o castigo um jeito de reparar a situação.

A questão do erro, da culpa e do castigo está bastante ligada com a questão da avaliação da aprendizagem na prática escolar. A avaliação tornou-se um instrumento de ameaça e disciplina da personalidade do educando, deixando de ser uma fonte de decisão de caminhos do crescimento e passando a servir de suporte para a imputação da culpa e do castigo.

Dentre os castigos utilizados atualmente pela escola, podemos destacar a reprovação (e a sua ameaça), como a mais perversa de todas. Por ser entendida de maneira errônea a avaliação tem servido para verificar os erros dos alunos. Esses erros são punidos com notas baixas que, por sua vez, implicam na reprovação. A reversão dessa situação exige que o elemento que estrutura a escola deixe de ser a reprovação para ser o aprendizado. De acordo com Luckesi (2005, p.59), “insucesso e erro, em si, não são necessários para o crescimento, porém, uma vez que ocorram, não devemos fazer deles fontes de culpa e de castigo, mas trampolins para o salto em direção a uma vida consciente, sadia e feliz".

A avaliação não pode simplesmente definir pela aprovação ou pela reprovação, pois a avaliação final representa um diagnóstico global do processo vivido.

A decisão da conveniência ou não de manter um aluno mais um ano num determinado ano de escolaridade deve ser coletiva, da equipe escolar, e não apenas de um professor. Levam-se em conta, nesse caso, o desempenho global do aluno e a pluralidade de dimensões que estão em jogo, como os benefícios da manutenção do aluno com seus pares para a socialização e o desenvolvimento equilibrado de habilidades, vivências e conveniências. A permanência de algum aluno num determinado ano de escolaridade por mais um ano deve ser considerada uma situação excepcional e de modo algum uma prática escolar habitual.

A seguir, destacamos como se processa a avaliação da aprendizagem em nossas escolas, o modo equivocado como vem sendo compreendido esse processo tão importante no desenvolvimento das atividades educativas, através de uma pesquisa em duas escolas públicas de Natal, no estado do Rio Grande do Norte. 


\section{METODOLOGIA DA PESQUISA}

Para o presente estudo, tomamos como sujeitos os professores dos anos finais do ensino fundamental dos colégios Instituto Ary Parreiras e Escola Municipal Terezinha Paulino de Lima. As escolas, juntas, são compostas por 105 professores nesse nível de ensino, dos quais foram escolhidos aleatoriamente 30 professores para preencherem a um questionário com seis perguntas abertas e fechadas. Quatro dos 30 professores não entregaram o questionário. Cada professor recebeu um questionário com as seguintes perguntas: Na sua concepção, o que é avaliação e qual a sua função?; Se o resultado da avaliação não foi o esperado, o que o(a) senhor(a) faz?; Em que o(a) senhor(a) se baseia para elaborar um instrumento avaliativo?; $O(A)$ senhor(a) acha que essa atribuição de notas reflete a aprendizagem do aluno? Por quê?; Qual a principal causa da reprovação?.

A seguir, apresentamos o resultado dessa pesquisa, almejando contribuir para a reflexão sobre a questão que se tornou hoje elemento fundamental na ação educativa.

\section{RESULTADOS E DISCUSSÃO}

Analisamos os resultados da pesquisa realizada nas escolas Instituto Ary Parreiras e Terezinha Paulino de Lima com os professores dos anos finais do ensino fundamental, etapa do ensino em que o grande problema que se apresenta é a reprovação, devido, sobretudo, ao modo equivocado de compreender e praticar a avaliação da aprendizagem, conforme podemos observar nos resultados a seguir:

\subsection{Na sua concepção, o que é avaliação e qual a sua função?}

Por ser uma pergunta aberta, não foi possível quantificar precisamente o resultado desse questionamento. Contudo, as respostas foram divididas em dois tipos, a saber, as que definem avaliação como meio de atribuição de notas, verificação de aprendizagem dos conteúdos ou verificação da capacidade intelectual do aluno, ou seja, a avaliação sendo vista como um instrumento de verificação; e as que definem a avaliação como um instrumento de reflexão sobre a prática educativa.

A figura 1 abaixo apresenta os dados da pesquisa:

\section{O que é avaliação?}

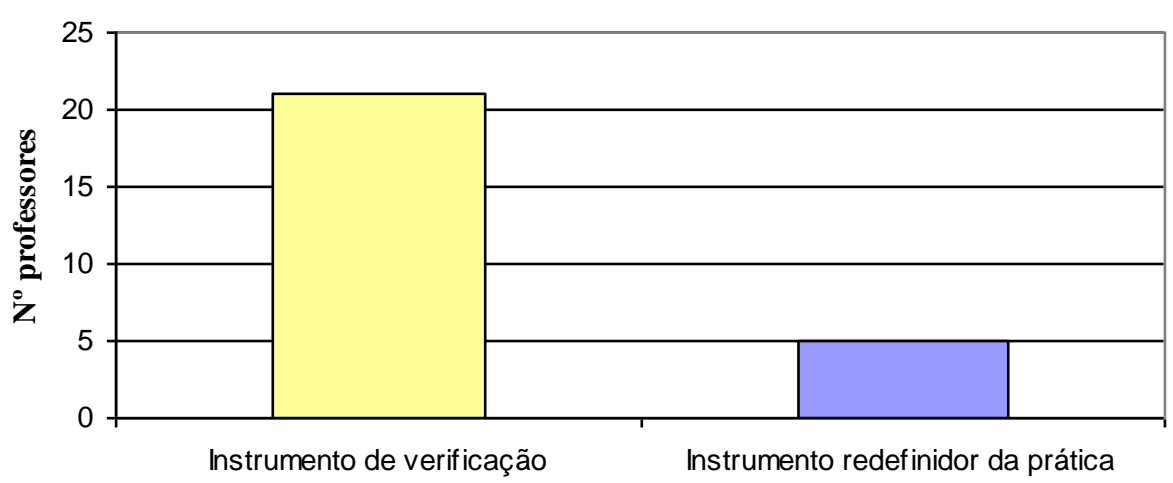

Figura 1 - Visão dos professores sobre a avaliação 
Grande parte dos respondentes (21 professores) disse que a avaliação era um instrumento de verificação da aprendizagem de conteúdos ou verificação da capacidade dos alunos e uma outra parte (5 docentes) disse que a avaliação era um instrumento que vai nortear o trabalho pedagógico. Essa realidade ficou expressa em falas dos sujeitos como:

"A avaliação é uma forma de verificar se os alunos realmente entenderam o que o professor deu."

"Avaliar é o processo pelo qual o professor analisa o aluno diante dos conteúdos estudados."

"Avaliação é um processo didático-pedagógico (...). Dentro do processo ensinoaprendizagem tem a função de atribuir nota."

"Avaliação é um processo contínuo e tem por função sinalizar os pontos do ensino-aprendizagem que devem ser revistos e reflexionados."

Os 21 professores que entendem a avaliação como um instrumento de medida, representam $81 \%$ do total de professores respondentes, enquanto que os que entendem que a avaliação é um meio de redefinição de sua prática educativa representam apenas $19 \%$.

Vemos uma grande variedade de definições e concepções de avaliação. Não existe consenso entre os professores sobre o que eles acreditam ser a avaliação. Muitos dos professores veem avaliação como um instrumento que mede capacidade ou desenvolvimento dos alunos e se limita a isso. Outros veem apenas a avaliação como um meio de atribuir notas.

Essas diferentes concepções, obviamente, produzem diferentes maneiras de intervenção no processo ensino-aprendizagem. Por exemplo, se o professor considera a avaliação o ato de atribuir notas, fazer testes e medir conhecimento ele nada irá fazer após constatar um determinado erro por parte do aluno (colocará apenas um certo ou errado no teste, atribuirá uma nota e pronto!). Se ele, porém, acreditar que a avaliação é um momento de reflexão sobre sua prática educativa, sua atitude já será outra. Em outras palavras, a concepção de avaliação dos professores é definidora de sua prática.

Assim, uma concepção equivocada de avaliação trará consigo uma prática avaliativa igualmente equivocada.

\subsection{Se o resultado da avaliação não foi o esperado, o que o (a) senhor (a) faz?}

Quando os professores foram perguntados sobre o que fazem após a realização de uma atividade avaliativa em que o resultado não foi o esperado, procuramos saber qual a atitude tomada pelo professor ao ter em mãos uma situação desfavorável ao aprendizado, ou seja, sabendo-se que não houve aprendizagem, de fato, o que é feito em seguida? E encontramos as seguintes respostas pelos professores:

- 14 professores disseram que explicam o conteúdo novamente para resolver a situação da falta de aprendizagem;

- 4 disseram passar um trabalho para ajudar a melhorar a nota baixa conseguida através da atividade avaliativa;

- 4 docentes apenas atribuem notas às atividades avaliativas e preenchem a caderneta; 
- 4 disseram usar a atividade como um diagnóstico da situação para replanejar a prática educativa.

Esse resultado pode ser verificado através da figura 2:

Após a utilização de um instrumento avaliativo você...

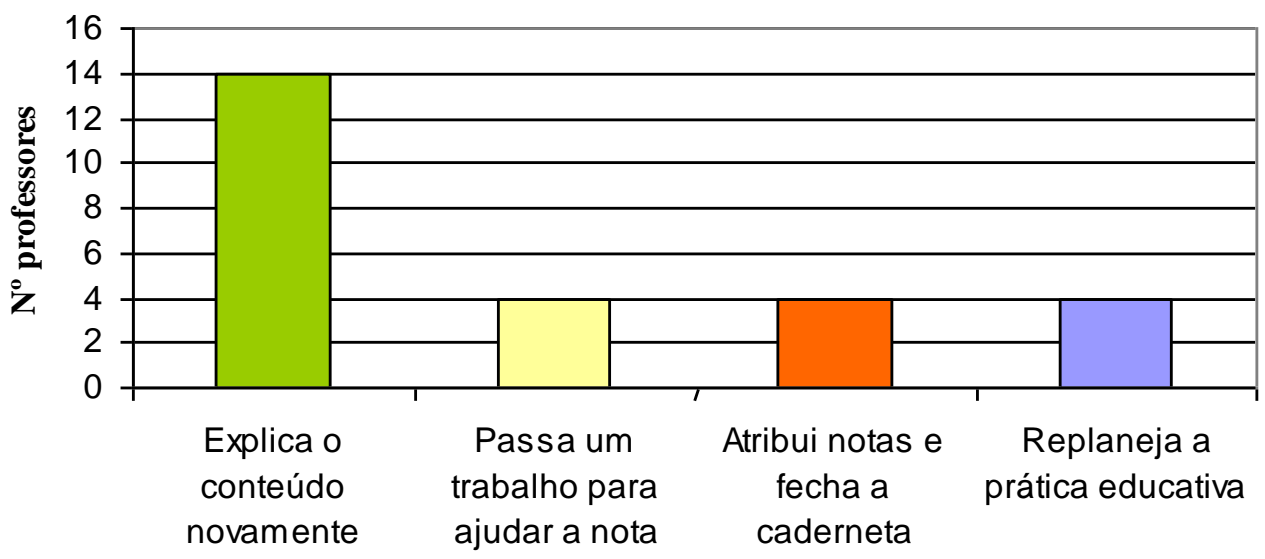

Figura 2 - Resultado da avaliação

Assim, vemos que a maioria dos professores (55\%), para resolver o problema da falta de aprendizagem, recorre a uma segunda explicação do conteúdo; $15 \%$ dos docentes dizem passar um trabalho para melhorar a nota insuficiente; outros $15 \%$ nada fazem, apenas registram o resultado e os $15 \%$ restantes disseram que analisavam a situação e replanejavam sua prática educativa como um todo.

É importante atentarmos para a maneira equivocada dos professores analisarem os resultados de uma avaliação: 14 professores disseram explicar o conteúdo novamente. Resta sabermos o que significa explicar o conteúdo novamente, ou seja, se o professor repete o que já foi feito ou se procura uma maneira de fazer com que os alunos aprendam através de uma proposta de atividade mais atraente. Além disso, deve-se observar se após essa "nova explicação" existe uma avaliação ou se ela é apenas uma formalidade sem sentido.

Significativa é a atitude tomada pelos professores que disseram passar um trabalho pra ajudar a nota dos alunos ou ainda os que disseram nada fazer além de anotar a nota na caderneta. Essa atitude demonstra claramente a preocupação exclusiva com a nota por parte dos professores. Não está sendo verificado como os alunos estão aprendendo, mas a nota que eles obtiveram.

\subsection{Em que o (a) senhor (a) se baseia para elaborar um instrumento avaliativo?}

Essa pergunta foi feita para compreendermos os motivos que influenciam os professores na escolha e elaboração de um determinado instrumento avaliativo. Analogamente ao questionamento anterior, os entrevistados poderiam escolher duas alternativas como resposta. A seguir, apresentamos as respostas apresentadas pelos professores questionados:

- 12 professores elaboram uma atividade avaliativa pela adequação do conteúdo a essa atividade;

- 12 se baseiam na sua experiência como professor para decidir sobre um ou outro instrumento avaliativo; 
- 10 professores disseram utilizar documentos oficiais como P.P.P. da escola, LDB ou PCNs como referência para elaborar um instrumento avaliativo;

- 1 docente disse escolher um determinado instrumento avaliativo pela sua facilidade de correção.

A figura 3 a seguir demonstra esse resultado:

Em que se basear para elaborar um instrumento avaliativo?

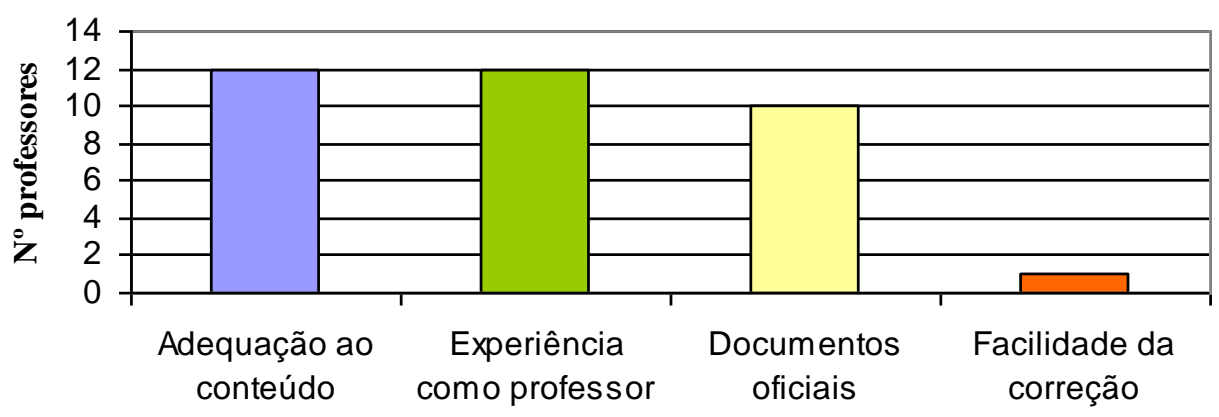

Critérios

Figura 3 - Em que é baseada a avaliação

Vemos que $46 \%$ dos professores escolhem um instrumento avaliativo pela sua adequação ao conteúdo estudado; a mesma quantidade de professores acham que sua experiência é um fator decisivo para escolher um instrumento de avaliação; $38 \%$ elaboram seus instrumentos se baseando em documentos oficiais e apenas $4 \%$ dizem escolher um instrumento avaliativo pela sua facilidade de correção. Assim, a maioria dos professores, para elaborar um instrumento avaliativo, se baseiam em sua experiência ou na adequação do conteúdo à atividade avaliativa.

Muitos erros, não somente em educação, mas em todas as áreas, acontecem devido à confiança em seus conhecimentos sem um estudo adequado. Os professores, sobretudo, confiam muito em sua habilidade e improvisação. Muitos professores utilizam as mesmas avaliações há anos. As questões são colocadas em provas e testes para pegar os alunos que não estavam prestando atenção às aulas. Elaborar um instrumento avaliativo através da experiência (o que significa isso?) é algo, no mínimo, aleatório.

7.4 O (A) senhor (a) acha que essa atribuição de notas reflete a aprendizagem do aluno?

Com esse questionamento, buscamos saber se os professores acham que as atividades avaliativas estão, de fato, avaliando seus alunos, ou seja, se as notas conseguidas pelos alunos nessas atividades são, realmente, a expressão do desenvolvimento do aluno. As respostas dadas pelos professores foram as seguintes:

- 11 professores disseram que as notas refletem, de fato, a aprendizagem dos alunos;

- 15 docentes disseram que as notas conseguidas pelos alunos nas atividades avaliativas não refletem as suas verdadeiras aprendizagens. 


\section{Notas refletem o apre ndizado?}

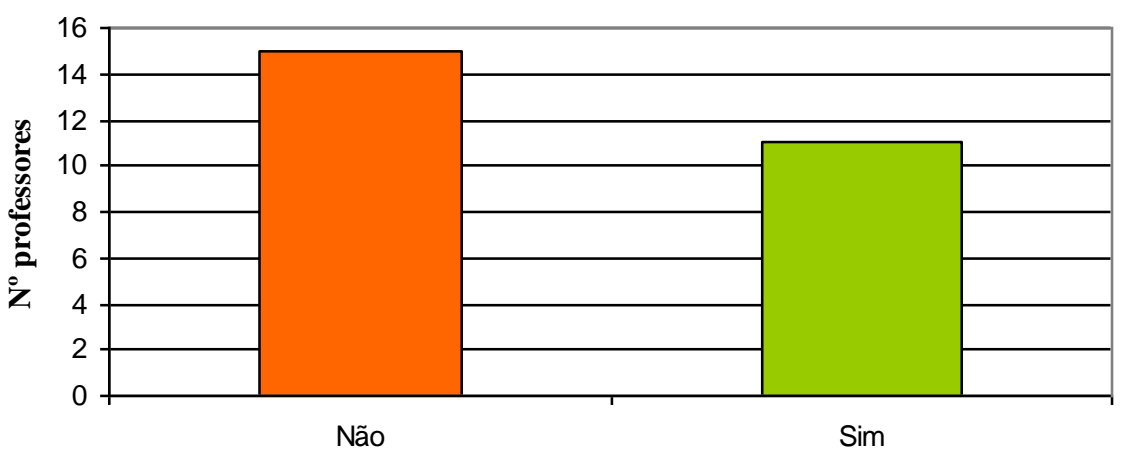

Figura 4 - Opinião dos professores sobre as notas dos alunos

Vemos, portanto, que a maioria dos professores (58\%) não vê as notas como um reflexo das aprendizagens dos alunos, enquanto que a outra parte (42\%) acha que as atividades avaliativas utilizadas pelos professores realmente servem para avaliar a aprendizagem. Assim, a maioria dos professores disse que nota não avalia a aprendizagem dos alunos.

De fato, como quantificar a aprendizagem de atitudes, por exemplo? $E$ ainda, se acreditamos que a avaliação deve ser um instrumento de redefinição ou replanejamento não podemos nos prender às notas, visto que dois alunos com nota 5 , por exemplo, podem ter necessidades totalmente diferentes. Cada caso deve ser analisado de acordo com suas especificidades e não através de uma nota que nada reflete sobre a verdadeira aprendizagem.

A "avaliação" está servindo para verificar a reprodução do que foi visto em sala de aula. A nota reflete justamente isso. A avaliação deve diagnosticar, informar e favorecer o desenvolvimento individual.

No processo de avaliação, devem-se considerar testes organizados pelo professor, coleção de produtos de trabalho do aluno, registros dos resultados de observação das discussões dos alunos, comentários, entrevistas com alunos ou grupo, análise da escrita, etc. Notas em testes e provas servem para provar domínio ou falta de habilidades dos alunos.

Alguns professores aplicam testes e provas surpresas a seus alunos, com a finalidade de puni-los. Notas não devem ter função punitiva e sim de diagnosticar possíveis interpretações errôneas dos conteúdos oferecidos, para poder retificá-los. Essa avaliação, completamente discriminadora, desconsidera o aspecto qualitativo da educação.

\subsection{Qual a principal causa da reprovação?}

Muitos são os fatores que levam um aluno à reprovação. Buscamos, então, saber qual a opinião dos professores sobre quem é, de fato, o principal responsável pela reprovação de um aluno. Obtemos o seguinte resultado:

- 16 professores (61\%) acham que o desinteresse do aluno é o principal motivo dos altos índices de reprovação nas escolas;

- 2 professores (8\%) apontam os pais dos alunos como o principal responsável pela fracasso escolar dos filhos;

- 1 professor (4\%) disse que a culpa é do próprio professor; 
- 7 professores (27\%) acham que todo o sistema de ensino é responsável pela reprovação.

Observe a figura 5 a seguir:

\section{Quem é o culpado da reprovação?}

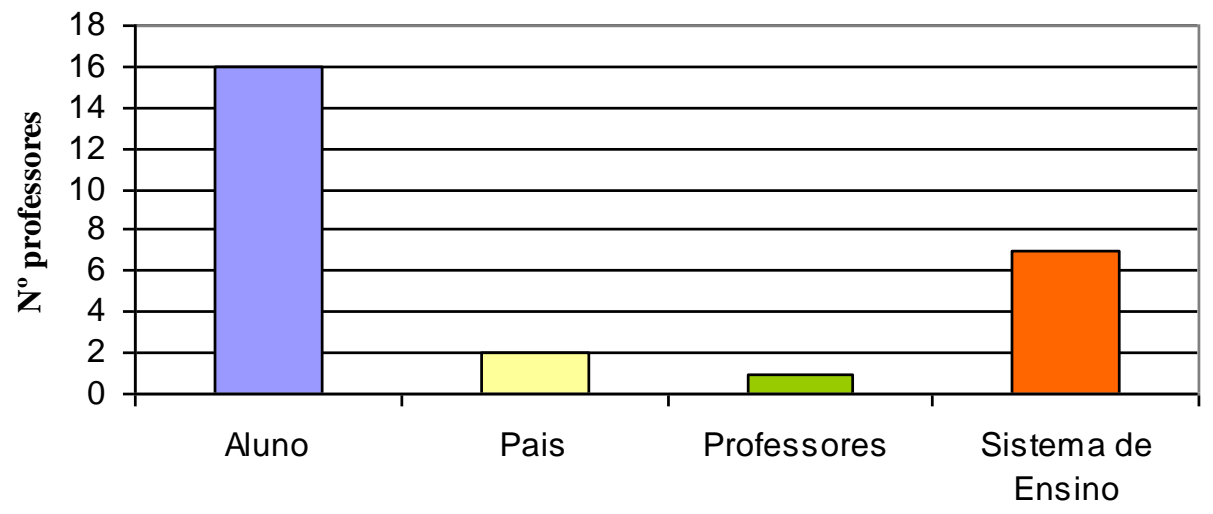

Figura 5 - 0 culpado pela reprovação na opinião dos professores

Vemos, através dos dados da pesquisa, que os professores consideram os alunos como o principal responsável pelo seu fracasso escolar. Os professores atribuem a culpa da reprovação aos alunos como se eles fossem o único responsável pela reprovação deles.

A atividade pedagógica que se dá na escola envolve um quase infindável conjunto de atividades, de recursos, de decisões, de pessoas, de grupos e de instituições, que vão desde as políticas públicas, passando pelas secretarias de educação, chegando à própria unidade escolar em que estão envolvidos o diretor, a secretaria, os professores, seu salário, suas condições de trabalho, o aluno, sua família, os demais funcionários, os coordenadores pedagógicos, o material didático disponível etc. Mas, no momento de identificar a razão do não aprendizado, apenas um elemento é destacado: o aluno.

Só o aluno é considerado culpado, porque só ele é diretamente punido com a reprovação. Como se tudo, absolutamente tudo, dependesse apenas dele, de seu esforço, de sua inteligência, de sua vontade.

\section{CONCLUSÕES}

O que se tem visto em nossas escolas é uma valorização exacerbada da avaliação, como se ela fosse a finalidade do ensino. É como se o ensino servisse para avaliar. Estuda-se não para aprender, mas para, ao ser avaliado, poder ser classificado (ou não) para a série seguinte.

Assim, a avaliação tem sido vista e utilizada como o fim da educação. Avalia-se para saber se deve promover ou excluir o aluno. Se o aluno obtiver o resultado esperado pelo professor (ou seja, notas acima da média), então se promove o aluno; caso contrário, ele será condenado a repetir a série, pois não obteve o resultado desejado e, por isso, será castigado com uma reprovação.

Esse tipo de avaliação, ao invés de auxiliar o processo de ensino-aprendizagem, serve somente para classificar os alunos em aptos e inaptos; reduzindo, assim, a avaliação a uma prova. 
É o que Luckesi (2005) chama de "pedagogia do exame": as atenções de pais, alunos, professores e sociedade estão voltadas para as provas (e na consequente promoção dos alunos), e não para o desenvolvimento do educando.

Corroborando com Libâneo (1994), vimos que a avaliação tem sido tomada como o ato de aplicar provas, atribuir notas e classificar os alunos; sendo, portanto, reduzida à cobrança daquilo que o aluno memorizou.

A avaliação tem que ser entendida de uma maneira muito mais ampla, pois é a parte mais importante de todo o processo de ensino-aprendizagem, visto que avaliar é mediar esse processo, oferecer recuperação imediata, promover cada ser humano, acompanhar cada aluno em seus progressos.

O grande desafio para construir novos caminhos é uma avaliação com critérios de entendimento reflexivo, conectado, compartilhado e autonomizador no processo ensinoaprendizagem. Desta forma, estaremos formando cidadãos conscientes, críticos, criativos, solidários e autônomos.

Como defende Luckesi (2005), não podemos mais pensar a avaliação como um instrumento de autoritarismo e classificação, que decide sobre a aprovação ou reprovação do aluno. Nesse contexto, a nota torna-se um fim em si mesma, ficando distanciada e sem relação com as situações de aprendizagem.

Mudar a nossa concepção se faz urgente e necessário. Devemos romper com padrões estabelecidos pela própria história de uma sociedade elitista e desigual. Neste sentido, mudar a prática avaliativa significa mudar toda nossa prática educativa.

Se as nossas metas são educação e transformação, não nos resta outra alternativa senão juntos pensar uma nova forma de avaliação, na qual predomina diagnóstico e tomada de decisão em favor do aprendizado em detrimento de constatação, classificação e estagnação.

\section{REFERÊNCIAS}

1. FREIRE, Paulo. Pedagogia da autonomia: Saberes necessários à prática educativa. 28. ed. São Paulo: Paz e Terra, 2003.

2. LIBÂNEO, José C. Didática. São Paulo: Cortez, 1994.

3. 2006. et al. Educação escolar: políticas, estrutura e organização. 3. ed. São Paulo: Cortez,

4. LUCKESI, Cipriano C. Avaliação da aprendizagem escolar: estudos e proposições. 17. ed. São Paulo: Cortez, 2005.

5. SANT'ANNA, Ilza M. Por que avaliar? Como avaliar?: Critérios e instrumentos. Petrópolis: Vozes, 1995.

6. ZABALA, Antoni. A Prática Educativa: Como ensinar. Trad. Ernani F. da F. Rosa. Porto Alegre: ArtMed, 1998. 